\title{
Communication Challenges in Distance Learning
}

\author{
Sediyaningsih $^{1}$, Patricia Marsha Adara ${ }^{2}$ \\ Universitas Terbuka, Indonesia ${ }^{1,2}$ \\ \{dianb@ecampus.ut.ac.id ${ }^{1}$, marsha.adara@gmail.com² ${ }^{2}$
}

\begin{abstract}
Communication ethic is one of the most important interaction aspects. how to respect and give strength to the interaction process. In face-to-face communication we can see each other's non verbal or gesture. The problem that arises is how these social or non-verbal signs will appear in online communication or in media interactions. This article analyzes the communication process in distance learning interaction between tutors and students in several online tutorial cases. This article will show how the face-toface learning material is transformed into digital learning material and how competencies and ethics becomes a crucial component for a digital learning material. Focusing on several online tutorial programs in 2019 as the base for the study, the analysis is performed using on the communication ethics theory, which gives an idea of how to communicate and respect each other on each interaction. Then the open distance learning process, which describes the learning process through the media, there is a separation between lecturers and students, and a social presence theory that emphasizes the presence of someone in every interaction, giving many meanings and the important thing is how they understand the media itself. This article presents challenges for experts and practitioners to pay attention to the ethics of communication in interacting through online media.
\end{abstract}

Keywords: communication ethics; open distance learning; social presence theory; media literacy in education

\section{Introduction}

Indonesia, as a country with more than 17 thousand islands and 260 million people, is a big country with diverse ethnicity, religion and culture. However, tertiary education system are finding it difficult to reach out to every areas of the archipelago. Up until 2018, the gross participation rate achievemnets (APK) of Indonesian tertiary education is only $32.5 \%$, far from other Asian countries such as Malaysia, Singapore and Korea with $90 \%$ of APK. Therefore the Minister of Research and Technology and Higher Education is targeting Indonesia to reach APK rate of $35 \%$ to keep up with the neighbouring countries aforementioned. Distance learning can be utilized to build a quality pool of human resources in Indonesia. This is as what has been performed by Universitas Terbuka (Indonesia's Open University or UT) distance learning program, that reached out a wide range of location, both in and out of Indonesia. The industrial revolution 4.0 pushes the education industry to adapt. The distance 
education system that has been running in UT have to evolve and get adjust with the 4.0 technological development.

The virtual world has developed significantly, including in the tertiary education field. Current transformations in the media landscape are challenging contemporary communication and media ethics in at least 2 ways. First, digitization of the media creates new ethical problems and new instruments of web-based media observation introduce new possibilities for media (self-)regulation and accountability [1]. This article looks more at the ethical problem in communication process through media. Hence it will be able to produce insights on the communication challenges of distance learning in higher education, focused on the relationship between etiquette and technology in distance learning education process.

\section{Methods}

This article will provide an explanation about the communication process that occurs between the tutor and student by looking at the conversation happening throughout the tutorial process. The data sample was taken from the online tutorial process of Communication Theory and Mass Communication subjects, by observing the interaction between the students and lecturers/tutors/educators throughout 8 discussion contents and 3 assignments from each class within 2 months. Data analysis is performed by looking back at the data sources such as online tutorial and the method is used. Interviews were conducted with several tutors and students to reinforce what was found.

\section{Results and Discussion}

\subsection{Conceptual Framework}

Scholar argues that in understanding media communication, it is always compared to face to face communication or interpersonal communication [2]. There are key differences amongst the two, namely the comfort of intimacy, social relations and uncertainty. Correlations between distance and interpersonal communication constructs of (1) conversational appropriateness, (2) social attraction, and (3) uncertainty reduction indicate that distance effects are significant in an online environment. Specifically, it was found that general conversational appropriateness mediated between uncertainty reduction and specific conversational appropriateness for individuals who moved closer together and farther apart over time, respectively.

The study result showed that there are 3 characteristics of face-to-face interactions or interpersonal communication that can be seen in long-distance interactions, which are the feasibility of interaction, the existence of social environment and the uncertainty that indicates online interaction. This article discusses the challenges of communication in interactions that occur in the process of distance learning, especially by using online media, through several theoretical bases such as communication ethics, open distance learning, social presence, and media literacy.

\section{a) Communication Ethics}


The process of communication in general always begins with an idea, looking for words that are appropriate to be made in one sentence, then think about how to convey it, ascertain whether the meaning that we expect can be retrieved well and the result of it. This is called "conduit" or a model of communication transmission [3]. An understanding of the other party is always needed because of the constant presence of interaction in the communication process. Etiquette is always present in communication, therefore, understanding etiquette is crucial for a successful communication.

Ethics and etiquette must be distinguished. Ethics is anything that creates a basis for someone to behave or act with another being. While etiquette is all forms of attitudes, behavior, and speech that is a reflection of a particular community or region. Etiquette is more to the rules in force, it cannot be generalized. But there is etiquette that is basic and general in nature and applies to wherever we are. Therefore ethics cannot be seen directly and is usually learned directly and naturally from the people who is closest and from the surrounding community that is very prevalent, while etiquette can be seen and studied thatis based on an internalized habit.

Education is the center of every human establishment. It is very necessary to form the character from a young age, because through education, the realization of meaning and goals in society can be more easily achieved. Education is not isolated but always carried and carried through the community [4]. Therefore, education is contextual, which becomes the main concern in this article as learning media network will result in a communication process that is not contextual. Students and lecturers or teachers coming from various backgrounds with diverse geographical and demographic conditions are united as one through media as the facilitator of interaction, and media itself is a tool that is not contextual in nature.

In the hyperpersonal communication model, under certain circumstances, interpersonal relationships can develop in computer mediated communication (CMC) to a greater extent than in face to face (FtF) interactions [5]. On the other hand, in face-to-face encounters, a wide variety of communication episodes do not comport well with a linier conception of the communication process. In face-to-face interaction, the distinction between influence agents and influence targets is virtually impossible to maintain. In this context feedback loops abound [6]. Distance learning is primarily marked by the separation of students and lecturers in the learning process. Interactions that occur through various modes both printed and non-printed. Learning is social, in which there are connection, communication, collaboration and creation. There are several characteristics of distance education, including the separation between student and teacher that causes no duration in the learning process, the influence of educational organizations in preparing and planning learning materials and learning assistance services, and the use of media technology to connect students and teachers in delivering teaching material [7]. Distance education is a process of teaching and learning media that causes the distance, separation of space and time, and able to make students feel as individualistic and not belonging to a group. The strength of distance learning is the focus on students [8].

The Social Presence Theory explains the effects of technological developments, especially telecommunications in the communication process, on the degree of calibration between two communicators using a communication medium [9]. This theory becomes popular when it is used to explain and understand how people interact through cyberspace or online. A study [5] found that interpersonal relationships can be built better through computer mediated communication (CMC). Another study found that in certain categories CMC was very effective in establishing adolescent independence [10]. It was added that communicating through the media would minimize the context so it was said to be de-contextual. 


\section{b) Media Literacy}

Media Literacy talks about how the understanding of the media, starting from its formation to the consequences. Media literacy is the knowledge, expertise and competence required to use and interpret media [11]. It includes critical literacy based on reflection, analysis and evaluation not only on the content and structural elements of text in the media, but also in terms of social, economic, political and political contexts and history, where messages are made, spread and used by an audience [12]. Media literacy concerns on the process of assimilating and using the code involve in the contemporary media system as well as the operative skills needed to properly use the technological system on which this codes are based (and as) the capacity to access, analyse and evaluate the power of the images, sound and messages with which we are faced every day and which play important role in contemporary culture. It include the individual capacity to communicate using the media competently [13].

\subsection{Communication Challenge in Universitas Terbuka's Distance Education}

Universitas Terbuka implements an open and distance education. Open means that anyone can become a student of UT as long as they have a high school diploma or equivalent. There are no restrictions on age and diploma year. With this openness, UT enable student diversity not only in terms of geographical and demographic, but also in terms of the level of competence when entering UT. The teaching and learning process in UT holds the same principle as face-to-face tertiary institutions. It is just differentiated by the method and learning assistance service. One of the various learning services that are available is the Online Tutorial (Tuton), which aids students with course preparation, introduction, material, discussion, and assignments.

\section{a) Preparation.}

As soon as students get enrolled at UT, they are provided with teaching materials that can be printed or obtained digitally. They are also engaged with an orientation program called the New Student Orientation (OSMB), provided training about distance learning skills (PKBJJ) and supported by a learning assistance service with tutorials, both face to face tutorials (by request) and online tutorial. During the 2 months of the course, students are given the opportunity to intensively interact with their tutors or lecturers, and within the final semester examination period students are given the choice to have an online or in class examination.

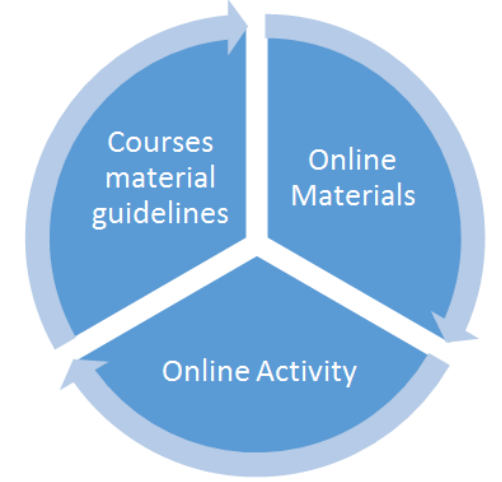

Fig 1. The flow of online tutorial preparation 
Figure 1 shows the online tutorial preparation flow. It is started by the provision of guidance to follow the tuton, writing initiation material, assignments and introductory discussions for the master class. It will then be distributed to other subject classes and then the tutorial will run for 2 months in each semester, usually at the beginning of the semester. The tutorial process is the most intensive interaction process during the lecture, in which there are 8 materials, 8 discussion forums and 3 assignments. Each discussion has a time limit, so that it can provide learning not only in terms of material, but also discipline.

\section{b) The Introduction Phase}

As with face-to-face learning, online learning also begins with introductions from tutors to students and vice versa, as well as between students. Each online tutorial class consists of 50 students. The following is an overview of the face-to-face learning approach with E-Learning taken from UT 2016 online tutorial training. The discussion of this article will be based on tuton 2019.1 from the Mass Communication (Komas) course with 9 classes and Communication Theory (Tekom) course with 7 classes. For this paper's analytical purpose, the sample will be taken from 2 classes; 1 from the Tekom class and 1 from the Komas class. The maximum number of students who take this tuton is 50 per class. So, the discussion is covering 100 students. Here is an example of Tuton from Mass Communication Class 01, 2019.1.

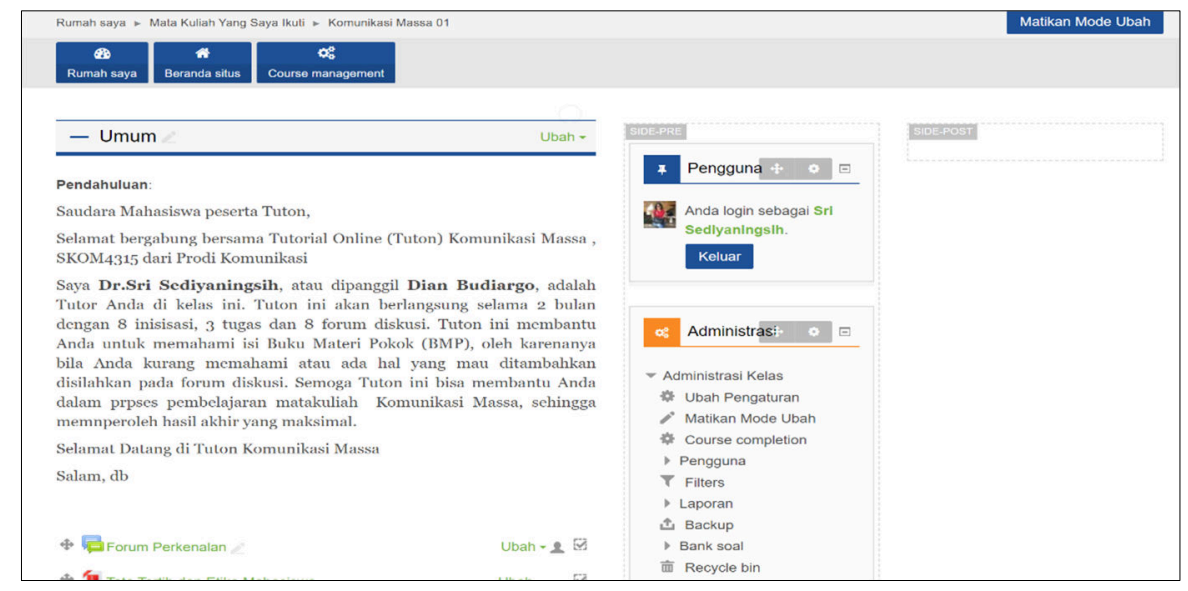

Fig 2. Screenshot of the sample of Online Tutorial

The starting page of the tuton is the tutor's greeting and also the student's introduction. Students' introduction is only performed by no more than $50 \%$ of the tutorial participants. Greetings from tutors are often not read, which is proven to be a lot and almost all students call their tutors "Bu Sri" even though in the beginning it was explained to "call me Dian". Then from the introductory forum, none of the students answered the introduction from their friends. They only filled in the introduction for themselves but did not respond to others, this shows that there were no interaction between the members who followed the Tuton.

\section{c) Material and Discussion}


There are 8 discussion materials or initiation materials that are taken from 9 modules of each subject. Those 8 discussion materials are selected based on the level of difficulty. There is no interaction occurring with the initiation material. Interaction occurs on the discussion forum. The message given by Tuton basically invites students for a discussion based on reading the subject matter book. Students are encouraged to discuss by giving a statement or question about what is important or difficult. In fact, almost all of the direction provided for the discussion did not generate a proper feedback. Students prefer to write whatever they want without reading the given discussion direction. So that communication does not occur as expected. The example above illustrates the discussion that happened at the existing class. Therefore interactions do not occur as expected.

\section{d) Assignment}

UT's students final grades are $100 \%$ contributed by their final examination result. However, students have the option to undertake the tutorial program that is delivered through Tuton to help improve their final examination grade. Online tutorial is one of the core learning delivery assistance provided by the distance education. Although the tutorial program is not a mandatory, students still need to register if they want to be part of it. The tutorial grades accounts for $30 \%$ to the final examination grade. It can only be applied when the student's score already exceeds $30 \%$ on their final examination. There are two types of tasks given in the tutorial; essay based and multiple choice based. In general, only $75 \%$ of the tutorial participants responded and submitted the assignments

By looking at the form of communication that occured during the tuton process, the average student does not know the lecturer very well. This leads them to indirectly have a dialogue with the machine. Sometimes there is a lack of respect as tutor's titles were not mentioned (no mention of $\mathrm{Mr} / \mathrm{Mrs}$ ). However, when their assignments have not been assessed, they immediately complained. They may even complaint directly to the Dean or Chancellor. There is no understandinf of communication etiquette throughout this process. As written above, etiquette is something is very situational. Therefore, situations or contexts are very difficult to be involved in distance learning, because educators are unable to see the actual condition or context of the student. Students and tutors perceive each word based on the meanings that exist in themselves.

\section{Conclusion}

From sample taken from the interaction process between Tutor and students in Tuton's 2019.1 it can be concluded that communication still face significant challenges in facilitating the process of teaching and learning of online higher education. This is caused by: (1) The loss of context in the process of interaction between tutors and students. The separation between tutors and students causes differences in location when interacting. Meanwhile, this situation or context at the location plays a huge role and provides a meaningful contribution in the communication process; (2) Meaning is different from the message delivered, because the communication process is not going well; participants just want a quick discussion without reading the news or previous dialogue; (3) The involvement in tutorial is only for the sake of the final grade as the tutorial participation helps students in increasing their final examination grade. Therefore, students who were involved in the tutorials are not there to expand their knowledge. This was reflected through the way students participate in the discussion and the 
quality of their assignments; (4) Lack of respect for tutors as lecturers, which is indicated by the response given during the discussion.

Communication etiquette in communication via online still requires more attention. The biggest challenge of online communication is the non-presence of context. Meanwhile in the world of education, the role of tutor/lecturer/teacher is not solely to teach, but also to educate that is maximized by context. Teaching is more about transforming science, while educating is more about providing concrete examples for students that is delivered through context, and this is missing from the online distance education. This challenges the communication experts to build communication etiquette on distance communication methods, especially for distance education.

\section{References}

[1] T. Eberwein, C. Porlezza. "Both Sides of the Story: Communication Ethics in Mediatized Worlds." Journal of Communication, Vol. 6., No. 2, pp. 328-342, 2016

[2] D.H. Krikorian, J.S. Lee, T.M. Chock, C. Harms. "'Isn't that spatial? Distance and communication in a 2-D virtual environment"' Journal of Computer-Mediated Communication, Vol. 5, No. 4, 2000.

[3] S. Priest, J. Godwin, M. Dahlstorm (Eds.). Ethics and Practices in Science Communication. Chicago: The University of Chicago Press, 2018.

[4] O. Ike. Ethics in Higher Education As A Tool For Discovering Our Ultimate Destiny. In D. Singh, C. Stuckelberger (Eds.). Ethics in Higher Education 1: Value Driven Leaders for the Future, pp. 17-30. Geneva: Globethics.net, 2017.

[5] J.B. Walther, J.F. Anderson, D.W. Park, D. W. "Interpersonal effects in computermediated interaction: A meta-analysis of social and antisocial communication." Communication Research, Vol. 21, No. 4, pp. 460-487, 1994.

[6] J.B Walther, P.M. Valkenburg. "Merging Mass and Interpersonal Communication in Interactive Communication Technology: A Symposium." Human Communication Research Vol. 43, No. 4, pp. 415 - 423, 2017.

[7] D. Keegan. The foundations of distance education. London: Croom Helm, 1986.

[8] C. Cavanough. Distance Education Success Factors. In M. Khosrow-Pour. Encyclopedia of Information Science and Technology,pp. 897-901. Hershey, PA: Idea Group Reference, 2005.

[9] J. Short, E. Williams, B. Christie. The social psychology of telecommunications. London: John Wiley \& Sons, 1976.

[10] Sediyaningsih. Pembentukan Identitas Sosial Remaja melalui Computer Mediated Communication. Dissertation. Universitas Indonesia, 2010.

[11] D. Buckingham. Media Education: Literacy, learning and contemporary culture. Cambridge: Polity Press, 2003.

[12] R. Hobbs. "The State of Media Literacy Education." Journal of Communication, Vol. 55, No. 4, pp. 865-871, 2005.

[13] D. Kamerer. "Media Literacy." Communication Research Trends, Vol. 32, No. 1, pp. 418, 2013. 